\title{
Bjerknes compensation in the Bergen Climate Model
}

\author{
Stephen Outten $^{1}$ (D) Igor Esau $^{1}$
}

Received: 9 June 2016 / Accepted: 6 November 2016 / Published online: 14 November 2016

(c) The Author(s) 2016. This article is published with open access at Springerlink.com

\begin{abstract}
The meridional transport of heat is a critical component of the Earth's climate system. If the total heat transported by the climate system is approximately constant, then the anomalies of heat transported by the atmosphere and ocean should be approximately equal and opposite, a scenario now called Bjerknes compensation. This has previously been found in two coupled climate models, with both showing multi-decadal variability in the heat transports. This work identifies Bjerknes compensation in the Bergen Climate Model, adding to the understanding of the robust features of Bjerknes compensation in coupled climate models. The atmospheric and oceanic heat transports are investigated in the 600-year control run of a fullycoupled global climate model. The presence of Bjerknes compensation is confirmed by the strong anti-correlation and equal magnitude of the anomalies of these heat transports. The heat transport anomalies contain a signal of multi-decadal variability. Since natural variability in global heat transport could mask anthropogenic climate change signals, understanding Bjerknes compensation is of socioeconomic importance. Using regression analysis the atmospheric and oceanic responses to the multi-decadal variability of the Bjerknes compensation signal are investigated. This highlights the importance of the marginal ice zones of the Greenland and Barents Seas as the critical location
\end{abstract}

Electronic supplementary material The online version of this article (doi:10.1007/s00382-016-3447-2) contains supplementary material, which is available to authorized users.

Stephen Outten

stephen.outten@nersc.no

1 Nansen Environmental and Remote Sensing Centre and Bjerknes Centre for Climate Research, Thormøhlens gate 47, N-5006 Bergen, Norway for coupling the atmosphere and ocean. During periods of increased heat transport in the ocean, these regions show decreased sea-ice, leading to increased fluxes and local temperatures, and giving rise to a thermal low-pressure center and a non-local high-pressure centre, thus changing the atmospheric flow on multi-decadal timescales.

Keywords Multi-decadal variability · Bergen Climate Model · Bjerknes compensation

\section{Introduction}

The meridional transport of heat, through the atmosphere and ocean, is a basic component for maintaining Earth's climate. It transports the energy entering at the top of the atmosphere (TOA) from the tropics to the polar regions, where longwave radiation to space allows the climate system to cool. Understanding the decadal to multi-decadal changes in these transports provides insight into the natural variability of the climate system. While the Fifth Assessment Report of the Intergovernmental Panel on Climate Change (IPCC AR5) states that there is very high confidence that industrial-era natural forcing is a small fraction of the anthropogenic forcing (Myhre et al. 2013), a good understanding of natural variability is still required in order to determine the proportion of the observed change that is attributable to anthropogenic forcing.

In 1964, Jacob Bjerknes proposed that large anomalies in the atmospheric heat transport should be balanced by opposing variations in the oceanic heat transport (Bjerknes 1964); a process later named Bjerknes compensation (BC). This comes about by assuming that the top-of-the-atmosphere fluxes and the ocean heat content are approximately constant, and consequently the total energy transport in 
the climate system should also be approximately constant. The sparse nature of oceanic measurements makes it difficult to accurately determine the variability in the oceanic energy transport, which would be required to directly identify BC in observations. Work by Shaffery and Sutton (2004, 2006) investigated BC in the pre-industrial control run of the Hadley Centre coupled climate model, HadCM3. They found that on inter-annual timescales the variability in the heat storage played a key role in the heat budget of the upper ocean, thus reducing the connection between the oceanic energy transport and the surface heat fluxes that would influence the atmosphere. On decadal timescales however they clearly identified $\mathrm{BC}$, finding a strong anticorrelation between the anomalies of heat transport in the atmosphere and ocean. They also showed that the compensation was strongest in the mid- to high-latitudes, peaking at around $70 \mathrm{~N}$. At these latitudes, much of the variability of the heat transports was confined to the Atlantic sector, and they went on to show the relationship between BC and the variability of the Atlantic meridional overturning circulation (AMOC) in the HadCM3 model.

Van Der Swaluw et al. (2007) expanded on the work of Shaffery and Sutton by formulating a quantitative measure of $\mathrm{BC}$, the Compensation Rate (CR), and by investigating the mechanism through which $\mathrm{BC}$ occurs in the model. They found that increased ocean heat transport caused an increase in SSTs and a decrease in sea ice coverage in the Greenland and Norwegian Seas. They proposed that the resulting increase in air-sea surface heat flux caused a decrease in the meridional temperature gradient in the atmosphere, thereby reducing the poleward heat transport.

More recently, work by Jungclaus and Koenigk (2010) has examined $\mathrm{BC}$ in the control run of a second model, ECHAM5/MPIOM (European Centre for medium weather forecast-HAMburg/Max-Planck-Institute Ocean Model). They also found that the atmosphere responded to changes in the ocean heat transport, although the compensation was weaker. Their work related changes in the large-scale flow patterns to long-term changes in the $\mathrm{CR}$, and determined that the compensation mechanism was associated with an AO-like pattern in sea-level pressure in the ECHAM5 model. They note that the degree of compensation determines the heat transport anomalies available to modulate the climate at high latitudes, and suggest that the atmosphere and ocean must act in concert (i.e. not compensating one another) to cause drastic warming or cooling, e.g. the early twentieth century warming, an idea shared by Held (2001) and his model of heat transport in the tropics.

Other studies have examined Bjerknes compensation using alternative approaches. Farneti and Vallis (2013) investigated heat transports in the atmosphere and ocean using a hierarchy of models, including the climate models, GFDL CM2.1. Unlike previous studies, Farneti and Vallis
(2013) averaged their heat transports over $20-70 \mathrm{~N}$, thereby merging the signals in the mid- and high-latitudes. Bjerknes compensation was identified in CM2.1 but was weaker than in previous studies, which had focused on the single latitude of peak compensation. Their work focused on the relationship between their signal for the Northern Hemisphere and the variability in the Atlantic meridional overturning circulation. Bishop et al. (2015) identified Bjerknes-like behavior in the North Pacific. However, as the authors state, it is not true $\mathrm{BC}$ since it is limited to a local scale balance.

Yang et al. (2013) used the Fast Ocean-Atmosphere Model, a general circulation model with low-resolution atmosphere and medium resolution ocean, to perform water-hosing experiments. By applying fresh water in the high latitude North Atlantic, they investigated how the atmosphere and ocean heat transports changed and hence how they compensated for one another. They found freshening the North Atlantic caused the Southern Hemisphere to warm leading to a shift in the atmospheric heat transport through atmospheric cells. A follow-up paper by Yang et al. (2015) decomposed the heat transports in the atmosphere and ocean into individual components. They confirmed that the atmospheric and oceanic heat transports showed significant anti-correlation, but this was not investigated further in their study. Liu et al. (2015) also employed an energy balance model to investigate the role of climate feedbacks on shaping the BC. Their work suggested that in their model, the compensation was bounded between a minimum that occurred at planetary scales and a maximum of perfect compensation that occurred at small scales. However, as they state, further work is needed to understand $\mathrm{BC}$ in more complex climate models or in the climate system itself.

This work identifies Bjerknes compensation in the Bergen Climate Model (BCM) pre-industrial control run for CMIP3. As with previous studies, this work focuses primarily on the Northern Hemisphere where the strongest compensation is found, allowing for comparison with the findings of those previous works and the highlighting of the notable differences found in the BCM. The model and calculations are explained in the next section, with an overview of the model results given in Sect. 3. Section 4 identifies the BC signal and compares it with other studies, while Sect. 5 examines the response in the atmosphere and ocean to this multi-decadal signal. Finally, Sects. 6 provides discussion and conclusions.

\section{Model description and data analysis}

This work examines decadal variability of the energy transport in the atmosphere and ocean of the 600 year pre-industrial control run of the Bergen Climate Model, the initial conditions for which were obtained from the end of an 
80 -year model spin up integration. The BCM is a global, fully-coupled, atmosphere-ocean-sea-ice general circulation model, which was used to produce simulations for the Coupled Model Inter-comparison Project (CMIP) (Covey et al. 2003). While a more complete description of the model is given in Furevik et al. (2003), a brief description of the major features is given here.

The atmospheric component of the BCM is the atmospheric general circulation model ARPEGE version 3 from METEO FRANCE (Deque et al. 1994). This is a hydrostatic, spectral model with semi-Lagrangian two-time level integration. For the control run discussed here, the atmospheric model was run on a linear grid with a truncated wave number of $T_{L} 63$ and 31 vertical hybrid levels that extend up to $10 \mathrm{hPa}$. Strong horizontal diffusion at the top of the model avoided the problem of spurious reflections.

The ocean component of the BCM is a modified version of the Miami Isopycnic Coordinate Ocean Model (MICOM) (Bleck et al. 1992). The MICOM model uses potential densities with reference to the surface pressure and, in the present control run, 35 vertical layers were used. The ocean grid had an almost regular horizontal grid spacing of $2.4^{\circ}$ due to the placement of the poles over central Siberia and central Antarctica. The grid was gradually reduced in the meridional direction to $0.8^{\circ}$ along the equator in order to better resolve the dynamics close to the equator.

In the BCM, the sea-ice model is an integrated part of the ocean model, consisting of one ice and one snow layer, assuming a linear temperature profile in each layer. The coupler between the atmosphere and ocean models is the Ocean Atmosphere Sea-Ice Soil (OASIS) coupler, through which the two models exchanged information once per day.

Despite the constant forcing being applied to the climate system in the model throughout the pre-industrial control run, it still experiences a steady drift. This is due to the GCM not being in complete equilibrium. The globalmean sea surface temperature undergoes a small but steady increase over the whole integration of the run, with an overall trend of about $0.03 \mathrm{~K}$ per century. This is due in part to a net imbalance at the top of the atmosphere between the incoming shortwave and outgoing longwave radiation of around $2.5 \mathrm{Wm}^{-2}$. However, only a small part of this imbalance transfers to the surface because the atmospheric dynamics within ARPEGE do not conserve energy (Otterå et al. 2009). The other possible mechanism for causing drift in the sea surface temperature is the long term feedback from the deep ocean, which will take centuries to come into equilibrium.

The sea surface salinity exhibits a steady increase of around 0.02 psu per century over the 600 year period. Much of this trend is balanced by growth of the ices sheets over Greenland and Antarctica as the model lacks a calving scheme that would otherwise freshen the global ocean in the model (Otterå et al. 2009). Combined with the non-closure of water cycle budget in the model, this leads to a small but steady increase in mean global salinity. Arctic sea-ice area over the 600 years, which is of relevance for $\mathrm{BC}$ and will be discussed later, shows little to no change over the model integration period. The Atlantic meridional overturning circulation shows both interannual and multi-decadal variability with a mean of about $20 \mathrm{~Sv}$ over the 600 years. The annual mean of these five diagnostics from the model are shown Supplemental Figure S1. A more detailed discussion of the model biases, along with an in depth breakdown of the model's ocean transports, has previous been given in Otterå et al. (2009).

The calculations of meridional atmospheric and oceanic heat transports follow the formulation of Shaffery and Sutton (2006). The implied meridional heat transport in the oceans, $\mathrm{H}_{\mathrm{O}}$, is derived by integrating the divergence of the zonally integrated surface flux into the ocean from the atmosphere, $F_{\text {sfc }}$, minus the time derivative of the ocean heat content $\left(\mathrm{O}_{\mathrm{HC}}\right)$. The implied meridional atmospheric heat transport, $\mathrm{H}_{\mathrm{A}}$, is found by integrating the sum of the divergences of the zonally integrated heat fluxes at the surface, $\mathrm{F}_{\text {sfc }}$, and the top of the atmosphere, $\mathrm{F}_{\text {toa }}$, thus:

$\frac{\partial H_{O}}{\partial y}=-\frac{\partial O_{H C}}{\partial t}-F_{s f c}, \quad \frac{\partial H_{A}}{\partial y}=F_{s f c}-F_{t o a}$

Monthly model output was used to calculate these heat transports, and an 11-year running mean was applied to smooth the data and emphasize the decadal variability, as in the work of Jungclaus and Koenigk (2010). The time derivative of the ocean heat content was calculated using the full depth of the ocean. Farneti and Vallis (2013) stated that the total meridional energy transport is not fixed a priori, thus to elucidate the quasi-constant nature of the compensation, they defined a total or planetary energy transport $\left(\mathrm{H}_{\mathrm{P}}\right)$ as follows:

$\nabla \cdot H_{P}=\nabla \cdot H_{O}+\nabla \cdot H_{A}$

Given the association found in previous studies between Bjerknes compensation and the Atlantic meridional overturning circulation, the implied meridional heat transport in the ocean was also calculated for just the Atlantic sector, $\mathrm{H}_{\mathrm{OAt}}$. This was done using the mask of ocean fraction that has been modified to create artificial boundaries for the Atlantic extending south from the southern tips of Africa and South America, and extending north from Novaya Zemlya (Supplemental Figure S2). It should be noted that the Nordic and Barents Seas were included in the Atlantic sector as defined by this mask due to their importance for the transportation of heat out of the Atlantic and into the Arctic (Smedsrud et al. 2013). 
Fig. 1 Comparison of the variance of the anomalies of zonally averaged net surface (blue) and top of atmosphere (red) fluxes in PW. 11-year smoothing is applied as described in Sect. 2
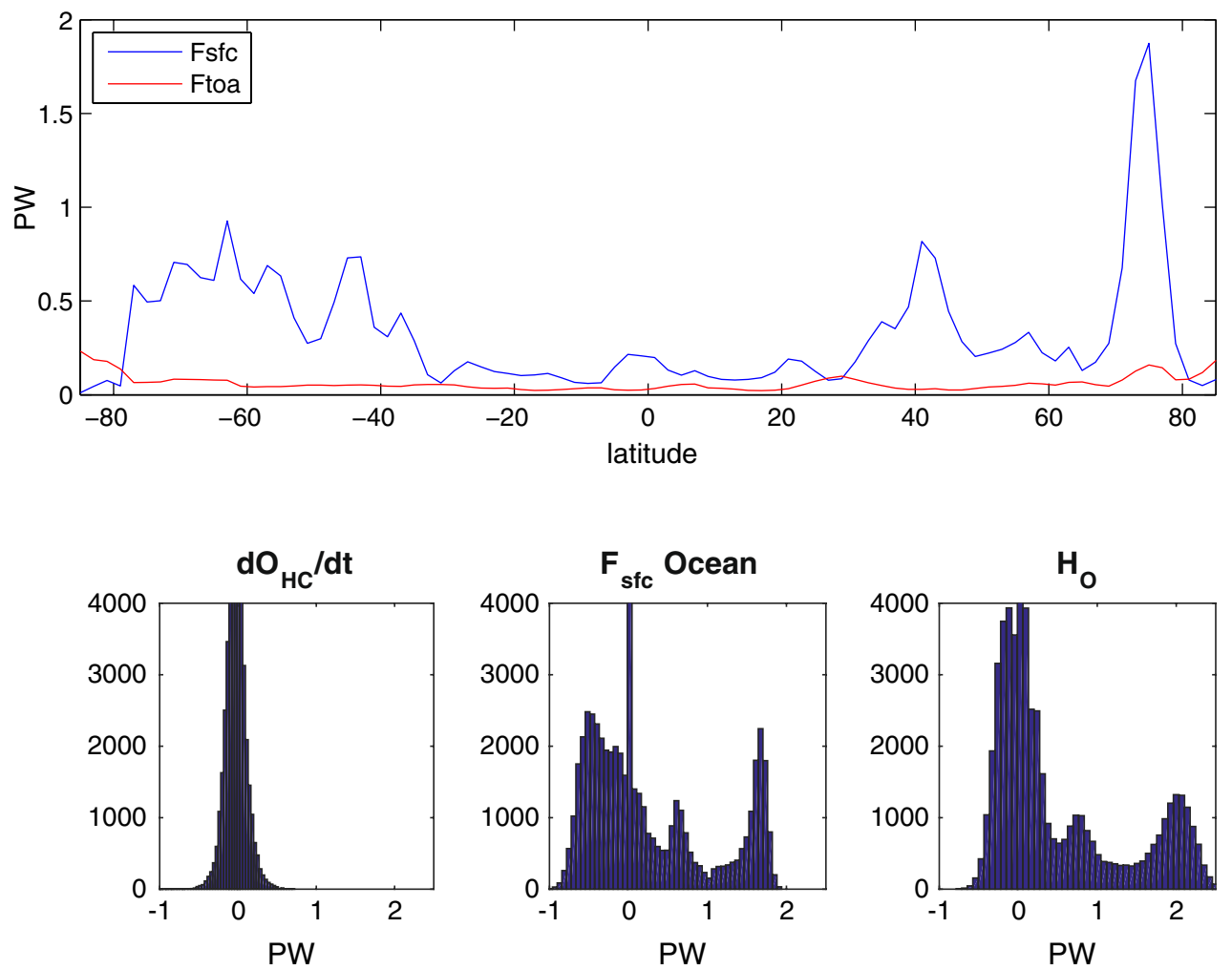

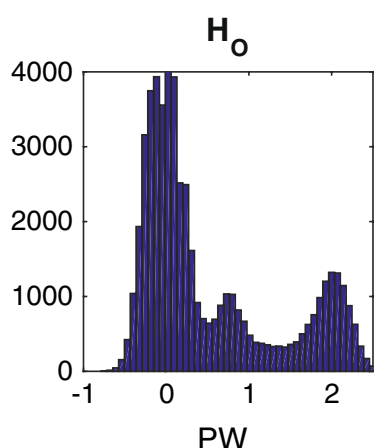

PW

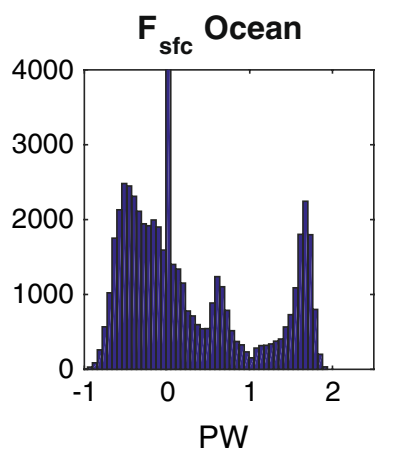

Fig. 2 Histogram of anomalies at all locations in rate of change of ocean heat content (left), ocean surface fluxes (middle), and implied meridional heat transport in the ocean (right). Anomalies are all in PW
The Compensation Rate $\left(\mathrm{R}_{\mathrm{C}}\right)$ is used in this work as a measure of the strength of the compensation between the heat transports in the atmosphere and ocean. The $R_{C}$ was defined by Van Der Swaluw et al. (2007) as a percentage of the maximum local transport as follows:

$R_{C}=(1-V) \times 100 \%$

with

$V=\frac{\left|d H_{A}+d H_{O}\right|}{\max \left(\left|d H_{A}\right|,\left|d H_{O}\right|\right)}$

where $d H$ denotes the anomaly of the respective heat transport compared to the time mean for each latitude.

\section{Heat transports in the $\mathrm{BCM}$}

Part of Bjerknes's original proposal included the assumptions that the flux at the top of the atmosphere did not vary greatly and that the ocean heat content remained approximately constant. To examine the first of these assumptions, the variance of the decadally smoothed anomalies of the zonally averaged net surface and top of atmosphere (TOA) fluxes are compared in Fig. 1. This shows that in the extra tropics, the variations in the surface fluxes were far greater than those of the TOA fluxes. This was not the case in the tropics where the variations in the TOA fluxes were comparable to those of the surface fluxes. A similar finding was made by Shaffery and Sutton (2006) and our findings for the BCM support their idea that BC might not be an appropriate model for the tropics as Bjerknes's first assumption only holds for the mid- to high-latitudes.

To confirm the second assumption, the spread in the rate of change of ocean heat content was compared to the spread in the surface fluxes (Fig. 2). The time derivative of the ocean heat content shows a narrow, Gaussian distribution centered on $0 \mathrm{PW}$, indicating that the ocean heat content is approximately constant and that the second assumption is reasonable. It should be reiterated that while the ocean heat content is approximately constant on decadal time scales, Shaffery and Sutton $(2004,2006)$ demonstrated that it may not be so on annual timescales. Figure 2 illustrates that most of the variability in the oceanic heat transport comes from the surface fluxes, as shown by the similarity of their distributions, suggesting that the conditions in the atmosphere must be suitable so as to trigger these large fluxes. The ocean heat transport and the surface fluxes have a broadly tri-modal pattern due to the strong and sharply defined regions of the ocean boundary currents.

Using Eq. (1), the mean atmospheric and oceanic heat transports have been calculated. From this point we focus primarily on the Northern Hemisphere where the strongest compensation is found. This also facilitates comparison to previous studies, which also focused primarily on the Northern Hemisphere. The heat transports for the Northern Hemisphere as a function of latitude is shown in Fig. 3. In 
Fig. 3 (Top) mean implied meridional heat transports in the atmosphere, $\mathrm{H}_{\mathrm{A}}$ (blue), and ocean, $\mathrm{H}_{\mathrm{O}}($ red $)$, in $\mathrm{PW}$ for the Northern Hemisphere. (Bottom) mean correlation between the $\mathrm{H}_{\mathrm{O}}$ and $\mathrm{H}_{\mathrm{OAt}}$ (black), and the mean compensation rate between $\mathrm{H}_{\mathrm{A}}$ and $\mathrm{H}_{\mathrm{O}}$ (magenta). Bold line in the bottom plot shows where the correlation is significant
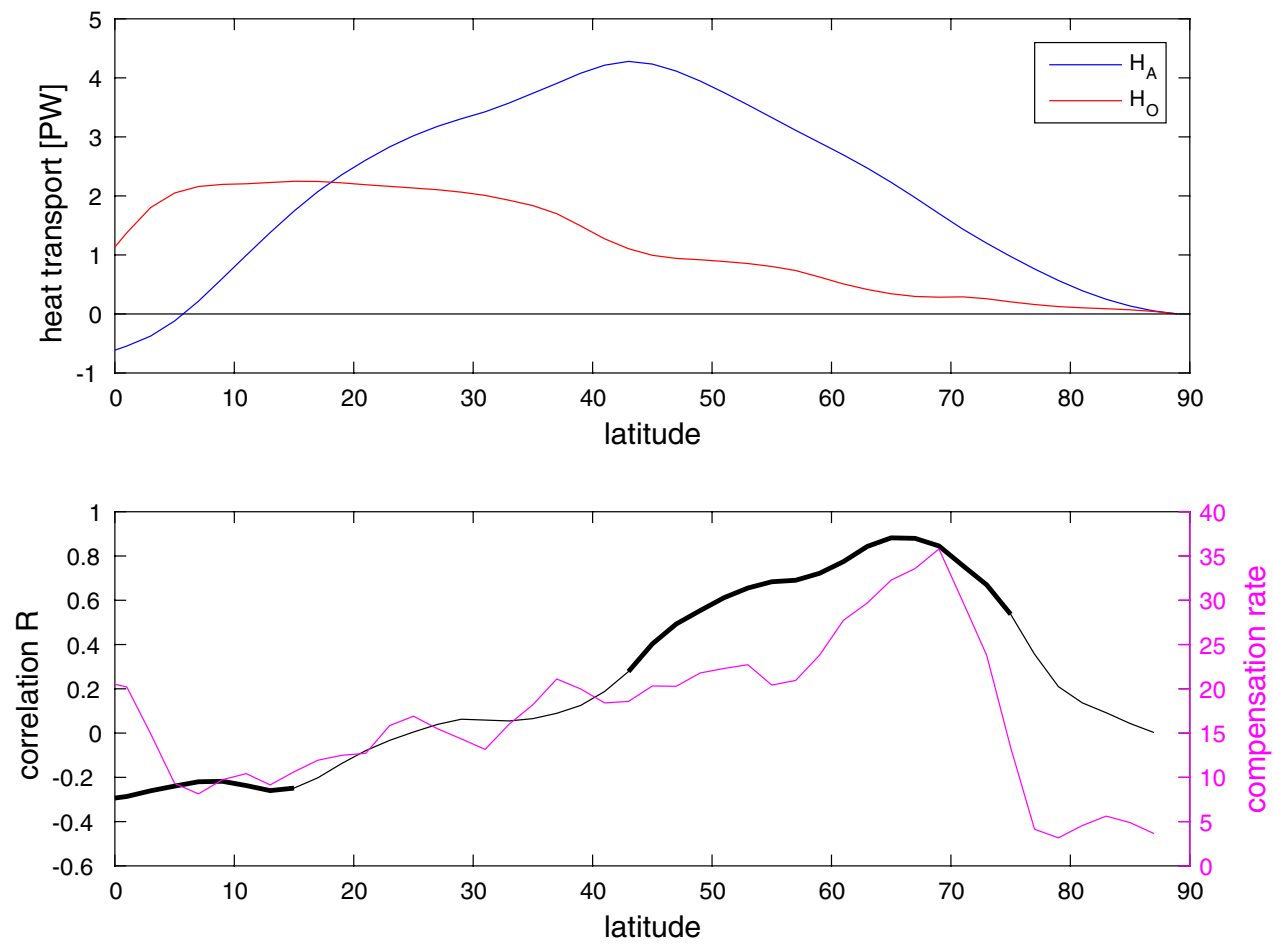

the Bergen Climate Model control run, the mean atmospheric heat transport has the distinctive symmetric shape around the equator, with peaks of $4.2 \mathrm{PW}$ at $43 \mathrm{~N}$ and 5.2 PW at $41 \mathrm{~S}$. These are similar to the values Trenberth and Caron (2001) estimated from the European Centre for Medium-Range Weather Forecast (ECMWF) reanalysis, who found peaks of approximately $4.5 \mathrm{PW}$ at $45 \mathrm{~N}$ and 5 PW at $40 \mathrm{~S}$. They also examined the National Centers for Environmental Prediction/National Centre for Atmospheric Research (NCEP/NCAR) reanalysis where they found a peak atmospheric heat transport of around $5 \mathrm{PW}$ in the Northern Hemisphere. While this is more comparable to the peak transports found in ECHAM5 by Jungclaus and Koenigk (2010), which exceeded 5 PW at 41 N, it is appreciably larger than the 3.8 PW peak found in HadCM3 (Van Der Swaluw et al. 2007), and is comparable to the $4.5 \mathrm{PW}$ peak found CESM 1.0 by Yang et al. (2015).

The mean ocean heat transport in the BCM reaches a maximum of $2.2 \mathrm{PW}$ at $17 \mathrm{~N}$. This is higher than the 1.4 PW in HadCM3, 1.6 PW in ECMWF, 1.8 PW in CESM 1.0, and 2.1 PW in NCEP/NCAR (Van Der Swaluw et al. 2007; Trenberth and Caron 2001; Yang et al. 2015). In ECHAM5, the oceanic heat transport into the Arctic was almost entirely confined to the Atlantic sector where it reached 1.2 PW, and again the ocean heat transport in BCM is higher (Jungclaus and Koenigk 2010). At around $70 \mathrm{~N}$, where previous studies have found a maximum in the $\mathrm{BC}$, the ocean heat transport is $0.24 \mathrm{PW}$. This compares well to the ECHAM5 model that has an ocean heat transport of around 0.28 PW at this latitude. Oliver and Heywood (2003) estimated the true ocean heat transport to be $0.2 \pm 0.08 \mathrm{PW}$ by examining a cross section in the Greenland Sea, extending from 65 to $77 \mathrm{~N}$. In summary, the heat transports in the atmosphere and ocean in the BCM are comparable to those found in the HadCM3 and ECHAM5 global climate models, the ECMWF and NCEP/NCAR reanalyses, and the ocean observation-based estimates from Oliver and Heywood (2003). As found by Farneti and Vallis (2013), the planetary heat transport, HP, is positively correlated with $\mathrm{HO}$, and the variability in HP is far smaller than the variability in either HA or HO (RMS variability of 0.28 PW in HP compared to 2.56 PW and 1.08 PW in HA and HO respectively).

\section{Identification of Bjerknes compensation}

In the BCM, the mean compensation rate, calculated from Eq. 3, peaks at approximately $36 \%$ close to $70 \mathrm{~N}$ (Fig. 3). For comparison, the compensation rate in HadCM3 was $55 \%$ at $70 \mathrm{~N}$, and in ECHAM5 was $28 \%$ at $70 \mathrm{~N}$ (Van Der Swaluw et al. 2007; Jungclaus and Koenigk 2010). This demonstrates that the strongest compensation between the anomalies of the atmospheric and oceanic heat transports occurs at around $70 \mathrm{~N}$ in all three models. The correlation between the heat transport in the ocean when calculated globally $\left(\mathrm{H}_{\mathrm{O}}\right)$ and when calculated for the Atlantic sector alone $\left(\mathrm{H}_{\mathrm{OAt}}\right)$ is also given in Fig. 3. The bold lines shows 
Fig. 4 Lag correlation plot for $\mathrm{H}_{\mathrm{A}}$ and $\mathrm{H}_{\mathrm{OAt}}$ as a function of latitude. Positive correlations show the ocean is leading the atmosphere. The shading represents regions where the significance exceeds $95 \%$ after in $\mathrm{H}_{\mathrm{A}}$ and $\mathrm{H}_{\mathrm{OAt}}$ accounting for autocorrelation

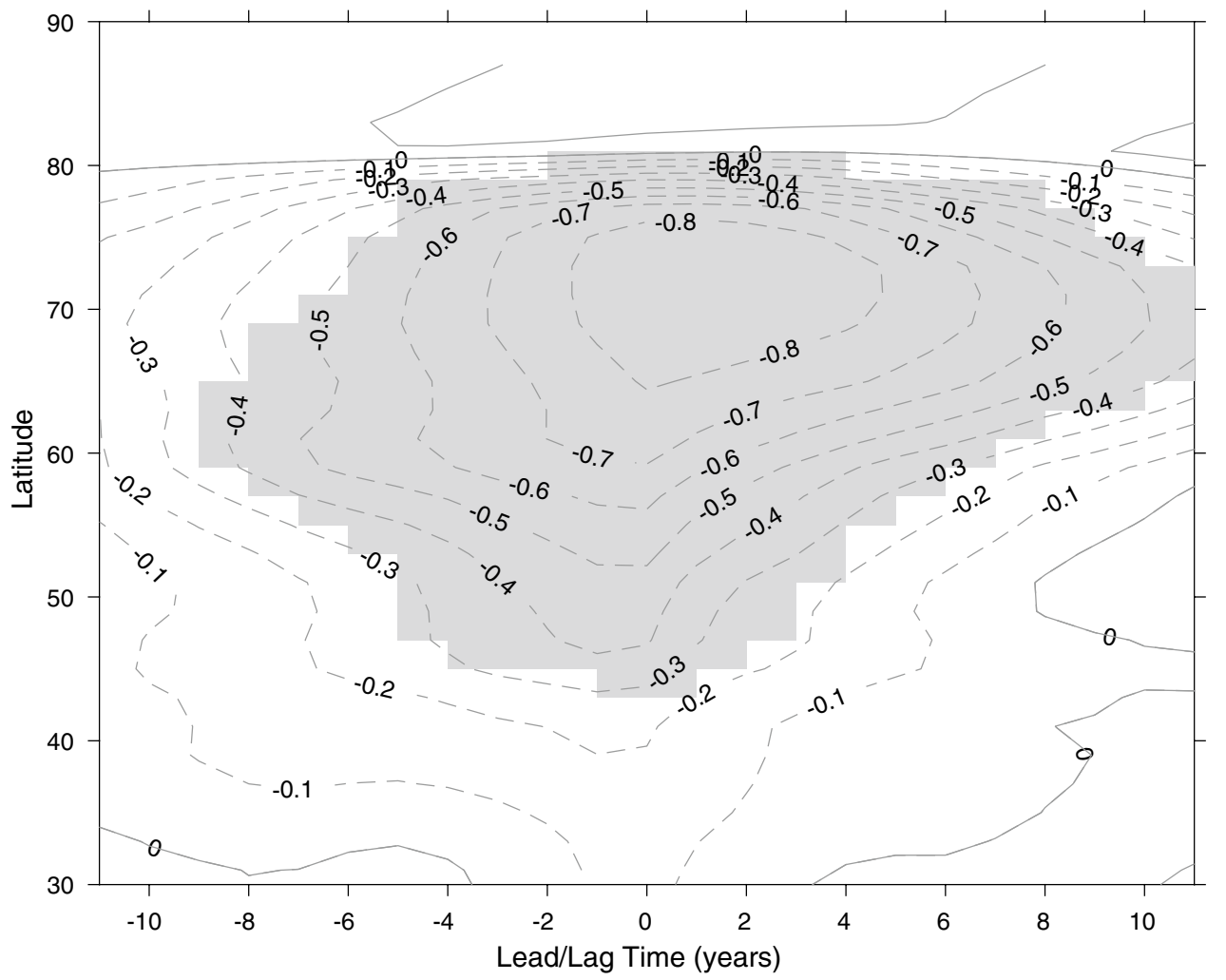

Fig. 5 Time series and correlation of anomalies in $\mathrm{H}_{\mathrm{A}}$ (blue) and $\mathrm{H}_{\mathrm{OAt}}($ red $)$ at $73 \mathrm{~N}$ where $\mathrm{H}_{\mathrm{OAt}}$ is leading by 1 year

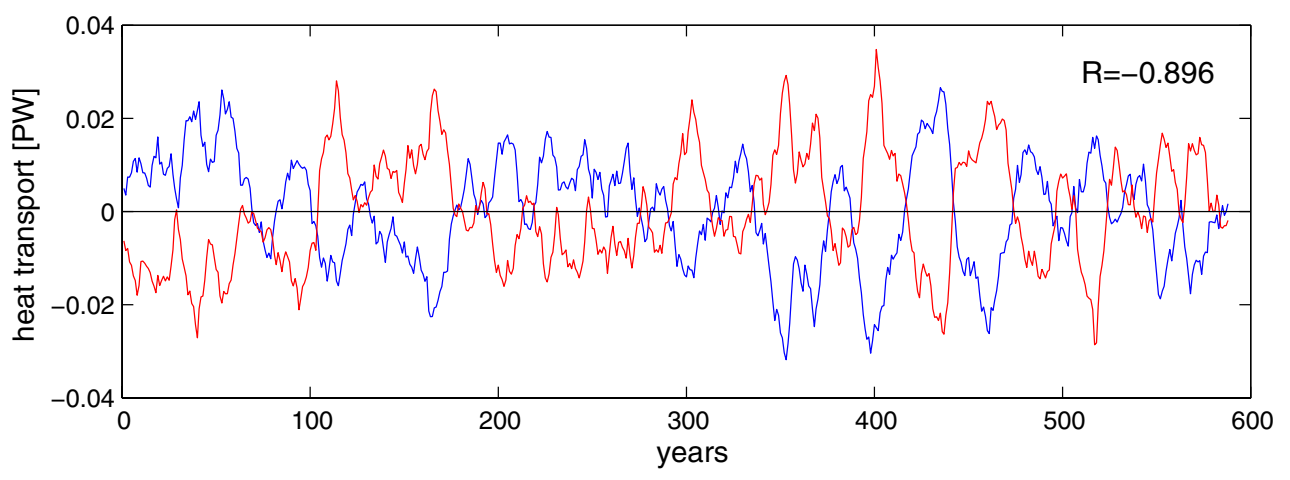

where the correlation is significant after accounting for the autocorrelation in the global and Atlantic ocean heat transports. The plot shows significant correlation between approximately 40 and $75 \mathrm{~N}$, indicating that at mid- to high-latitudes, most of the variability in $\mathrm{H}_{\mathrm{O}}$ comes from the Atlantic sector. This is especially true at around $70 \mathrm{~N}$. Therefore, to examine BC in the BCM, we will focus on the compensation that occurs between the global atmosphere and the ocean in the Atlantic sector. However, the results of a parallel analysis using the globally calculated $\mathrm{H}_{\mathrm{O}}$ are given in the supplemental information and show very similar findings.

Figure 4 shows the lag-correlations between $\mathrm{H}_{\mathrm{A}}$ and $\mathrm{H}_{\mathrm{OAt}}$ for the mid- and high-latitudes of the Northern Hemisphere. The strongest anti-correlation occurs at $73 \mathrm{~N}$ and with the ocean leading the atmosphere by 1 year. This is slightly further north than in HadCM3 or ECHAM5 that both had a maximum around $70 \mathrm{~N}$, however they did show a similar leading of the ocean by around 1 year (Van der Swaluw et al. 2007; Jungclaus and Koenigk 2010). At decadal timescales, Bjerknes suggested that the ocean should drive the atmosphere through air-sea fluxes (Bjerknes 1964). This has recently been shown to be the case in observations from the North Atlantic, especially in the wintertime (Gulev et al. 2013). A similar lag-correlation plot between $H_{A}$ and $H_{O}$ is shown in Supplemental Figure S3. For the globally calculated $\mathrm{H}_{\mathrm{O}}$, the peak correlation again occurs at $73 \mathrm{~N}$ and with a 1-year lag between the ocean and the atmosphere.

The anomalies of $\mathrm{H}_{\mathrm{A}}$ and $\mathrm{H}_{\mathrm{OAt}}$ at $73 \mathrm{~N}$ for the 600 years of the model run are shown in Fig. 5 with the 1 year lag 
applied. The strong anti-correlation $(\mathrm{R}=-0.89, p<0.05)$ between the two heat transports highlights how the variations in the atmospheric heat transport compensate for the variation in the oceanic heat transport, and vice versa. This is in agreement with the proposed mechanism for Bjerknes compensation that the anomalies of heat transported around the climate system by the atmosphere and ocean should be equal and opposite. It is interesting to note that while the mean heat transports in the atmosphere and ocean at $73 \mathrm{~N}$ are 1.17 and $0.21 \mathrm{PW}$ respectively, the anomalies in these heat transports have approximately the same magnitude. This means that in the atmosphere, the anomalies are approximately $1 \%$ of the mean heat transport, while in the ocean the anomalies are approximately $10 \%$ of the mean heat transport.

Also apparent in Fig. 5 is the 50-65 year oscillation (confirmed with Fast Fourier Transform) present for much of the time. Similar multi-decadal oscillations were seen in the ECHAM5 and HadCM3 models. While the anomalies of atmospheric and oceanic heat transport are opposed to each other much of the time $(86 \%)$, there are brief periods when they have the same sign and thus complement one another. These periods are all short lived and generally occur when changing from one heat transport being dominant to the other. This highlights the unstable nature of the situation where the atmosphere and ocean compliment one another in terms of heat transport anomalies.

All of the features discussed here are similar when the globally calculated $\mathrm{H}_{\mathrm{O}}$ is examined (Supplemental Figure S4), e.g. the multi-decadal oscillation is still present, the anti-correlation peaks at $73 \mathrm{~N}$ and is still strongly correlated $(\mathrm{R}=-0.88, p<0.05)$. This pronounced and significant negative correlation that characterizes the Bjerknes compensation found in the BCM is also found in HadCM3 ( $\mathrm{R}=-0.84$ ) (Van Der Swaluw et al. 2007), and in ECHAM5 ( $\mathrm{R}=-0.62)$ (Jungclaus and Koenigk 2010). Farneti and Vallis (2013) found a weaker anti-correlation $(\mathrm{R}=-0.52)$ in the CM2.1 model; however, they compared the heat transports when averaged over $20 \mathrm{~N}$ to $70 \mathrm{~N}$, thereby merging the mid-latitude and high-latitude signals. When applying a similar averaging to the $\mathrm{BCM}$, the correlation drops to $\mathrm{R}=-0.46$, which is comparable to the findings of Farneti and Vallis (2013).

Given that the heat transports are properties of the Earth system and that an 11-year smoothing has been applied, it is reasonable to assume that these fields will show significant autocorrelation. This can artificially increase the correlation by reducing the degrees of freedom, which for a two-tailed $t$ test are given by the number of independent observations. Following Zeiba (2010), the effective number of observations is given by:

$n_{\text {eff }}=n\left(1+2 \sum_{k=1}^{n-1} \frac{n-k}{n} \rho_{k}\right)^{-1}$ where $n$ is the number of observations and $\rho_{k}$ is the autocorrelation at lag $k$. Using this effective number of observations, we calculate the bound of significant correlation to be approximately $\mathrm{R}=0.37$, at the $95 \%$ level.

\section{Atmospheric and oceanic response}

Thus far we have established that Bjerknes compensation does exist in the pre-industrial control run of the Bergen Climate Model, that the BC signal is strongest around $70 \mathrm{~N}$, and that most of the variability in the ocean at this latitude is from the Atlantic sector. In this section, we will examine the regional response in the atmosphere and ocean to this multi-decadal oscillation in heat transport anomalies by regressing the time series of BC shown in Fig. 5 onto maps of various atmospheric and oceanic fields. To facilitate this, we will consider the situation when the BC is in the phase of a positive heat transport anomaly in the Ocean.

When the ocean in the Atlantic sector is transporting more heat towards the high latitudes, there is a reduction in the sea-ice concentrations in the Greenland and Barents Seas (Fig. 6), which both have a large area of marginal ice zone (MIZ) in the BCM. The reduced sea-ice cover results in increased heat flux from the ocean to the atmosphere. A small change in the flux is also visible near the Bering Strait as this is also a MIZ region. Two bands of changes in fluxes are also visible in the storm track regions of the Atlantic and Pacific. Both extend eastward, from Newfoundland and the coast of Japan respectively, and both consists of a band of increased fluxes north of a band of decreased fluxes, suggesting that there is a small northward shift in the storm tracks in these locations. However, the highest responses in air-sea flux are confined to the Greenland and Barents Seas. These strong fluxes cause a pronounced rise in the local surface air temperature (Fig. 6).

Figure 6 underlines the importance of the MIZ as being the main location where heat anomalies in the ocean can cause such a strong response in the atmosphere. When the globally calculated $\mathrm{H}_{\mathrm{O}}$ is regressed onto the same fields, a very similar pattern is observed (Supplemental Figure S5). The responses in sea-ice, surface fluxes, and surface air temperatures are still restricted to the Greenland and Barents Seas, with little to no response observed in the Pacific sector. Previous studies have also identified the Greenland and Barents Seas as being the locations with the strongest atmospheric response (Van der Swaluw et al. 2007; Jungclaus and Koenigk 2010). For sea-ice concentration, the response in HadCM3 was centered in the Greenland Sea between Svalbard and Greenland, with a smaller response limited to the northwestern sector of the Barents Sea (Van der Swaluw et al. 2007, their Figure 8). In ECHAM5, the sea ice response was centered in the northeastern Barents 

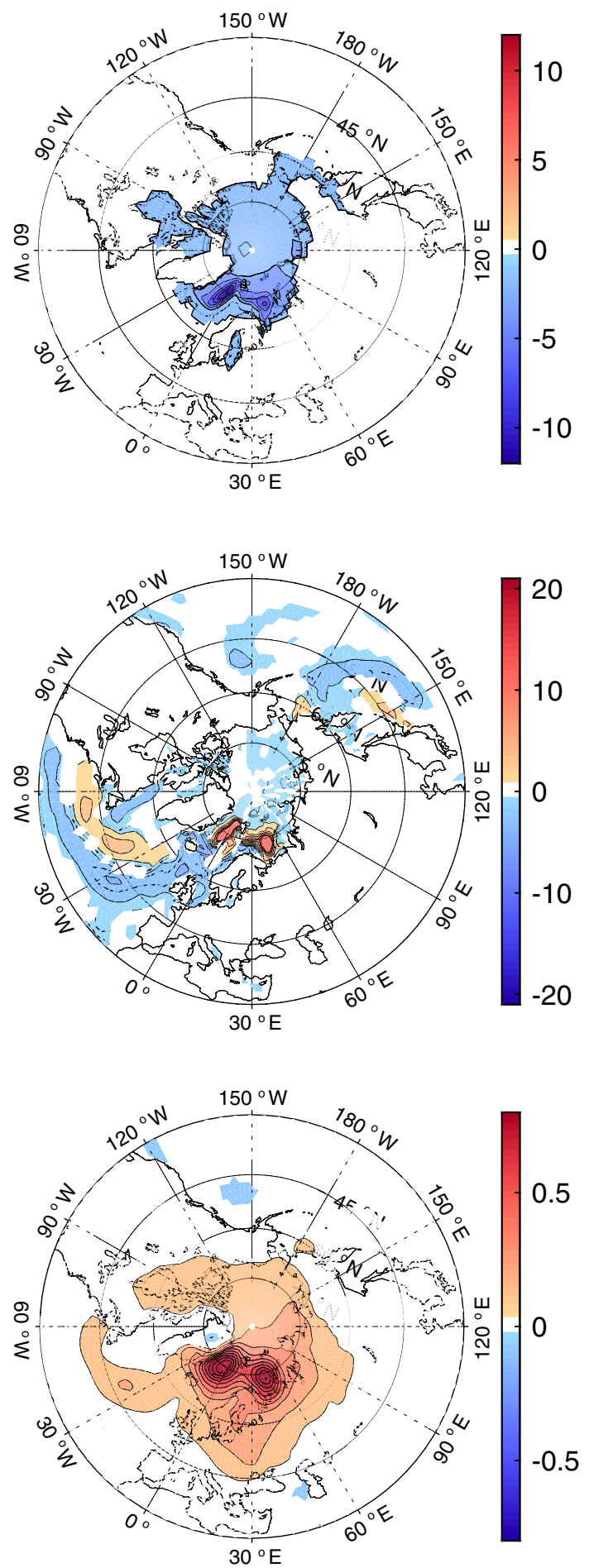

Fig. 6 Maps of $\mathrm{H}_{\mathrm{OAt}}$ regressed onto sea-ice concentration (top), surface flux (middle), and surface air temperature. Contour levels and units are $2(\%), 2\left(\mathrm{Wm}^{-2}\right)$, and $0.1(\mathrm{~K})$ respectively, per standard deviation of $\mathrm{H}_{\mathrm{OA}}$. White regions are below the $95 \%$ significance level

Sea, with a weaker response extending south through the western Barents Sea and east and south through the Greenland Sea (Jungclaus and Koenigk 2010, their Figure 6d).
ECHAM5 also showed some response in the Kara Sea, which is not seen in either the HadCM3 model or the BCM. The differences in location of response of sea-ice concentration, and hence surface fluxes and surface air temperature, are attributable to the differences in location of the MIZ between the models.

There is a strong relationship between the $\mathrm{BC}$ signal and the heat anomalies in the North Atlantic. This can be seen in the correlation of $\mathrm{BC}$ and the Atlantic Multidecadal Oscillation (AMO) index defined as the areaweighted average sea surface temperature (SST) over the North Atlantic between $0 \mathrm{~N}$ and $70 \mathrm{~N}$. The AMO index is strongly correlated with $\mathrm{H}_{\mathrm{OAt}}$ at $73 \mathrm{~N}$, reaching a peak correlation of $\mathrm{R}=0.41, p \leq 0.05$ when the AMO leads $\mathrm{H}_{\mathrm{OAt}}$ by 2 years (Fig. 7). As the ocean currents transport a positive heat anomaly northwards from the mid-latitudes to the Greenland and Barents Seas, the SST and surface air temperature (SAT) will be in local equilibrium for much of the distance. This small temperature difference constrains the flux of heat from the anomaly into the atmosphere. The presence of sea-ice at high latitudes causes a decoupling of the SST and SAT, but as the heat anomaly reaches the Greenland and Barents Seas, it causes a reduction of the sea-ice cover and exposes the heat anomaly to the cold Arctic air. The large difference in SST and SAT triggers large heat fluxes from the ocean to the atmosphere. Hence it is the locations where the warm ocean currents meet the MIZ that the strongest responses in the atmosphere are seen.

To investigate the atmospheric response to localized heating over the Greenland and Barents Seas, the BC signal, taken here as the variability of ocean heat transport, is regressed onto the sea level pressure (Fig. 8). As the large-scale response in the atmosphere may be outside of the mask used to create $\mathrm{H}_{\mathrm{OAt}}, \mathrm{H}_{\mathrm{O}}$ is used instead of $\mathrm{H}_{\mathrm{OAt}}$, however the results of regressions using either $\mathrm{H}_{\mathrm{O}}$ or $\mathrm{H}_{\mathrm{OAt}}$ are very similar, as demonstrated by comparing Fig. 6 and Supplemental Figure S5. Lead-lag analysis was undertaken to determine that the strongest response is found when the ocean heat transport leads the sea level pressure by 2 years, indicating that the pattern shown in Fig. 8 is the atmosphere responding to increased ocean heat transport. During periods of anomalously high meridional heat transport in the ocean, a thermal low is found over the Barents Sea. There is also a high-pressure centre found over northwestern Greenland that extends south along the west coast of Greenland and over the Labrador Sea. Since no response was seen previously over this region in the regressions of sea-ice concentration, SAT, and surface fluxes (Fig. 6), this high-pressure center is a non-local response to the heating anomalies in the Greenland and Barents Seas.

A study by Kaspi and Schneider (2011) demonstrated with an idealized general circulation model that localized 
Fig. 7 Time series and correlation of $\mathrm{H}_{\mathrm{OAt}}$ at $73 \mathrm{~N}$ in $\mathrm{PW}$ (blue) and the AMO index in $\mathrm{K}$ (red) $73 \mathrm{~N}$ where the AMO is leading by 2 years
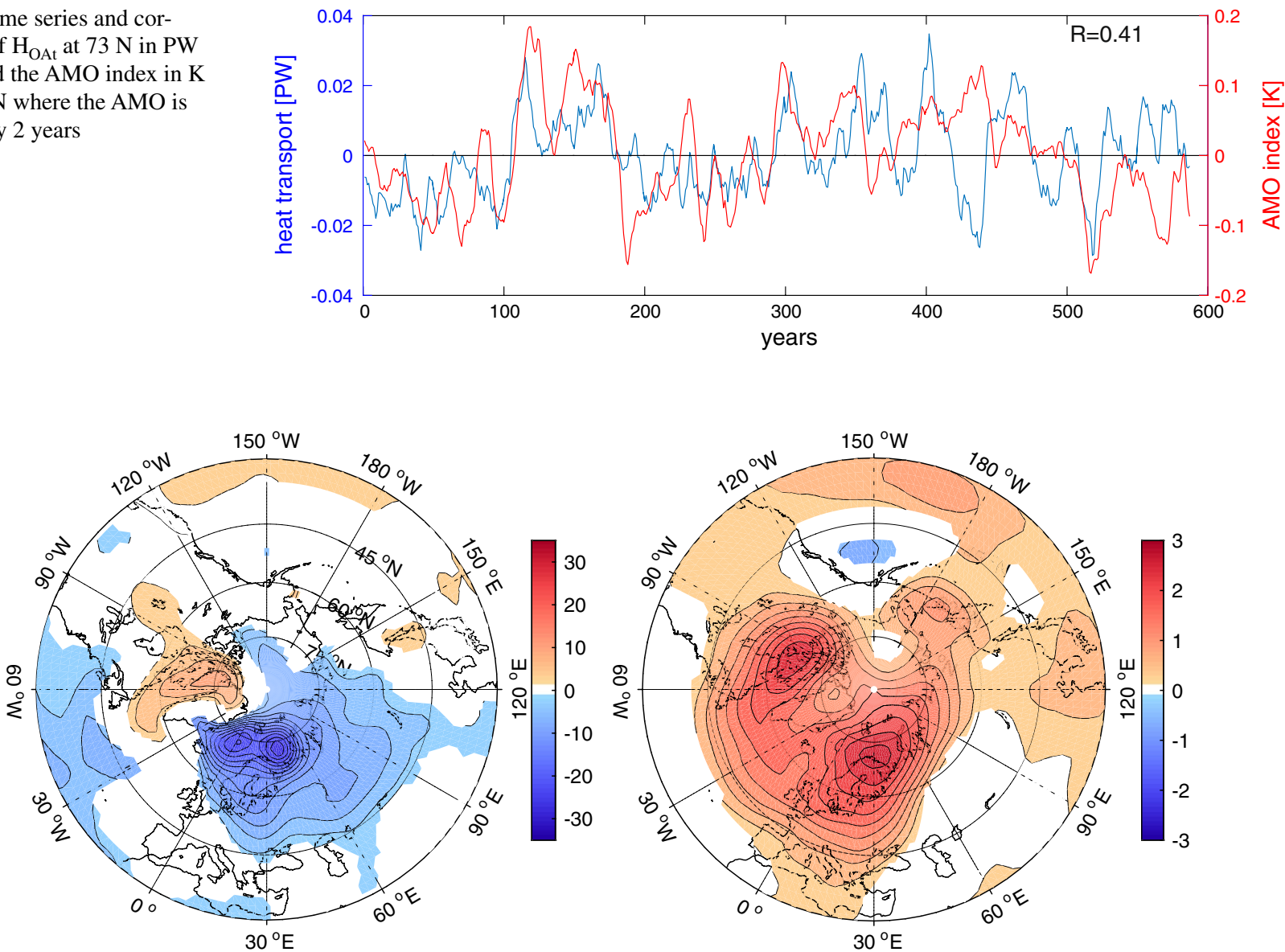

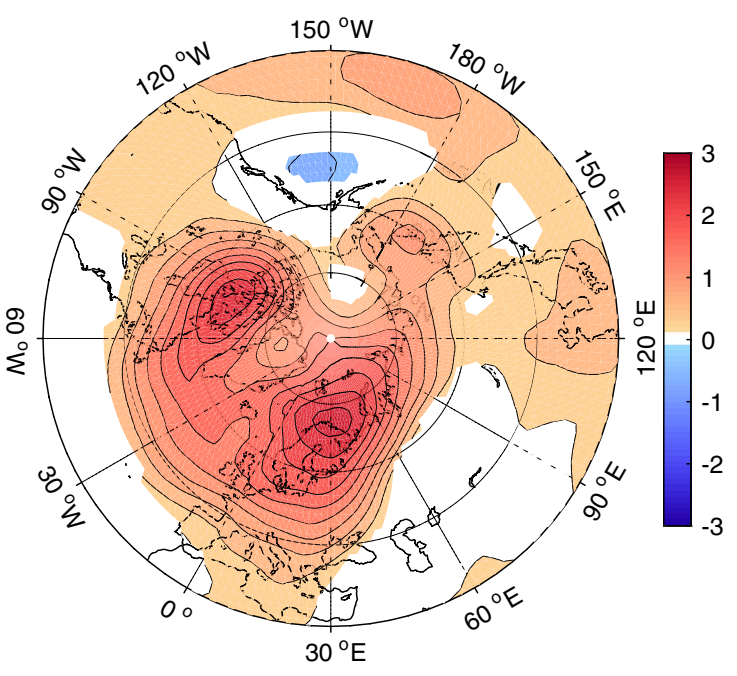

Fig. 8 Maps of $\mathrm{H}_{\mathrm{O}}$ regressed onto sea-level pressure (left) and geopotential height at $500 \mathrm{hPa}$ (right), where $\mathrm{H}_{\mathrm{O}}$ is leading by 2 years. Contour levels and units are $2(\mathrm{~Pa})$ and $0.25(\mathrm{~m})$ respectively, per standard deviation of $\mathrm{H}_{\mathrm{OA}}$. White regions are below the $95 \%$ significance level

heating of the atmosphere gives rise to stationary high and low pressure centers to the west and east of the heating respectively. This is similar to the response seen in Fig. 8 around the heating in the Greenland Sea. Their findings suggested that there should be a pronounced cooling to the west of the region of heating under the high-pressure center. The regression of SAT in Fig. 6 does show a small, but significant cooling located over northern Greenland under the core of the high-pressure center, in accordance with the theory proposed by Kaspi and Schneider. They proposed that these surface highs and lows are manifestations of near-stationary Rossby waves, induced by the localized atmospheric heating and propagating westwards (Hoskins and Karoly 1981; Kaspi and Schneider 2011). When the BC signal is regressed onto the geopotential height at $500 \mathrm{hPa}$, a strong response is found over the Labrador Sea and Barents Sea, suggesting a change in the Rossby waves in these regions (Fig. 8). However, further study is required to confirm whether or not a change in Rossby waves is induced by the oscillations of meridional heat transports.
A response to the $\mathrm{BC}$ signal was also identified in the North Atlantic sub-polar gyre. Following the approach used by Born and Mignot (2012), an index for the strength of the sup-polar gyre (SPG) was created by taking the absolute value of the local minimum of the depth-integrated stream function in the sub-polar North Atlantic (Fig. 9). Comparing this index to the heat transport anomalies in the atmosphere, $\mathrm{H}_{\mathrm{A}}$, shows them to be robustly anti-correlated, $\mathrm{R}=-0.52$ (Fig. 9). This indicates that when the atmosphere undergoes periods of increased heat transport, the SPG is weaker. Lag correlation was undertaken to confirm that the strongest correlations between the atmosphere and the SPG were found with no lead or lag. Interestingly, while the strength of the SPG shows good correlation to $\mathrm{H}_{\mathrm{A}}$, the oceanic heat transport anomalies, $\mathrm{H}_{\mathrm{O}}$, show no significant correlation $(\mathrm{R}=0.15)$, suggesting that the changes in the strength of the sub-polar gyre are associated with changes in the atmospheric heat transport and not the oceanic heat transport. Previous studies have shown that the strength of the sub-polar gyre is strongly influenced by the atmosphere through the surface wind stress (Curry et al. 1998; Böning 
Fig. 9 (Top) depth integrated stream function averaged over 600 years. Contours every $5 \mathrm{~Sv}$, negative contours shown as dotted. (Bottom) time series and correlation of $\mathrm{H}_{\mathrm{A}}$ at $73 \mathrm{~N}$ in $\mathrm{PW}$ (blue) and the sub-polar gyre index in $\mathrm{Sv}$ (red)

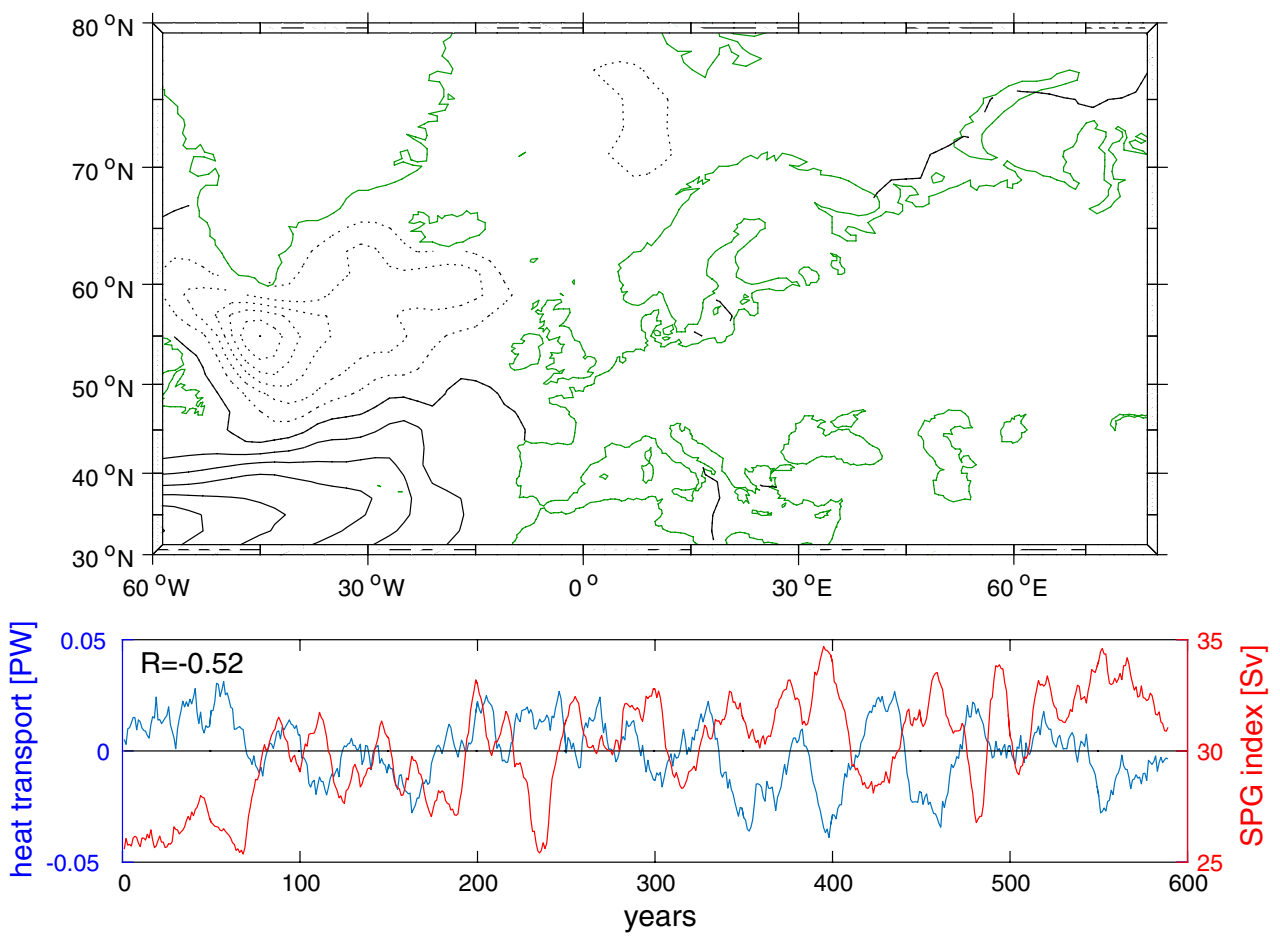

et al. 2006). A new study is currently beginning to investigate BC in the CMIP5 models and the links to the subpolar gyre will be investigated further there.

\section{Discussion and conclusions}

We have identified Bjerknes compensation in the 600year pre-industrial control run of the Bergen Climate Model. The strongest anti-correlation between the global atmospheric and oceanic heat transport anomalies is $\mathrm{R}=-0.89, p \leq 0.05$, with the ocean leading the atmosphere by 1 year. The mean Compensation Rate at this peak was $36 \%$. This peak occurs at around $70 \mathrm{~N}$ where most of the variability is from the Atlantic sector, despite $\mathrm{BC}$ being a global phenomenon. As found by the previous studies with other climate models, the heat transports have a multi-decadal signal (Shaffery and Sutton 2006; Jungclaus and Koenigk 2010; Yang et al. 2015; Farneti and Vallis 2013).

The atmospheric and oceanic responses to the $\mathrm{BC}$ signal were explored and the marginal ice zone has been identified as a key location for the ocean to drive the atmosphere due to the break down of the decoupling effect of complete sea-ice cover. Interestingly, the sea-ice variability associated with $\mathrm{BC}$ is almost completely contained in the Atlantic sector, with little to no variability seen in the Pacific sector. When sea-ice cover in the Barents and Greenland Seas is reduced during periods of anomalously high ocean heat transport, strong fluxes to the atmosphere cause heating and the generation of a thermal low extending east of the region of heating with a high pressure system to the west. This pattern of low and high pressure is inline with the ideas proposed by Kaspi and Schneider (2011), however further research is required to investigate the relationship between the variations in heat transports and the changes in the large-scale flow.

Perhaps the most important question still outstanding is does the multi-decadal signal of Bjerknes compensation exist in the real world? Jacob Bjerknes put forward the theory for Bjerknes compensation based on simple idealized energy balance arguments and this study, like those that came before it, only identify BC in model simulations, most often only in control runs which have constant forcings. In the real climate system, $\mathrm{BC}$ may be disrupted by any combination of forcings or patterns that exist. Currently, there are insufficient ocean observations to accurately calculate the total ocean heat transport. Bishop et al. (2015) identified Bjerknes-like compensation over the North Pacific during the wintertime in the Community Earth System Model and discuss its impact on the Kuroshio Extension. They also found similar changes to the Kuroshio Extension in the observations suggesting that Bjerknes-lke compensation may be present. However, as they state, this is not true $\mathrm{BC}$ given it is a localized compensation between the atmosphere and ocean.

The patterns of atmospheric and oceanic response discussed in this paper could be used to guide a search for the BC signal in the real climate system. The models indicate that there should be a multi-decadal oscillation in 
temperature and sea ice concentration over the Barents and Greenland Seas. This is in agreement with both ECHAM5 and HadCM3. Historical observations and estimations for the twentieth Century do suggest a 60 year oscillation in the temperature over the Barents Sea (Smedsrud et al. 2013), but such observational records are too short to statistically confirm the presence of the signal. Klimenko (2008) examined the reports of Russian and European seafarers dating back 600 years to build a temperature reconstruction for the Eastern Barents Sea region. While this does suggest a multidecadal oscillation in temperature similar to that shown in the models, there is great uncertainty on these results. Fauria et al. (2010) created a reconstruction of sea-ice extent in the Nordic Sea using tree rings and ice cores from Svalbard that contained a statistically significant $60-80$ year oscillation. Divine and Dick (2006) also identified a 60-80 year oscillation in the sea ice extent using 250 years of observations. Miles et al. (2014) extended this work to establish a signal of pervasive and persistent multidecadal ( $60-90$ year) fluctuations in the Greenland Sea, which reflect covariability between sea ice and Atlantic multidecadal variability as represented by the AMO index. Moreover, they provided evidence of similar covariability through a previous few centuries. The Atlantic multidecadal variability record has also been extended back for almost a century before the observational period using multiple paleo reconstructions (Svendsen et al. 2014). This observational evidence supports recent modeling studies that have suggested that Arctic sea ice is sensitive to the anomalies of the North Atlantic ocean heat transport. Currently however, there is a lack of observations and paleo records with sufficient temporal and spatial resolution to confidently identify the Bjerknes compensation signal in the climate system. A difficulty also arises from the fact that over land, the signal is in many places above the tree line, limiting the usefulness of tree-ring paelo reconstructions in the identification of the $\mathrm{BC}$ signal in the real world. However, there is now active research on shrub dendrochronology that may resolve this issue (Weijers et al. 2010). The identification of the multi-decadal variability of $\mathrm{BC}$ in the climate system is of socio-economic importance, not only because the natural variability may unknowingly impair the detection of anthropogenic climate change, but also because of its potential applicability to future endeavors to develop decadal climate prediction systems.

Acknowledgements This work was funded by the Norwegian Research Council bilateral collaboration with International Arctic Research Centre, Fairbanks, Alaska, USA, 227137: and MEDEVAC and BASIC projects funded by the Bjerknes Centre for Climate Research (BCCR). This research uses data provided by the Bergen Climate Model (BCM) project (www.bcm.uib.no) at the BCCR, largely funded by the Research Council of Norway and running on NOTUR computational facilities.
Open Access This article is distributed under the terms of the Creative Commons Attribution 4.0 International License (http://creativecommons.org/licenses/by/4.0/), which permits unrestricted use, distribution, and reproduction in any medium, provided you give appropriate credit to the original author(s) and the source, provide a link to the Creative Commons license, and indicate if changes were made.

\section{References}

Bishop SP, Bryan FO, Small RJ (2015) Bjerknes-like compensation in the wintertime North Pacific. J Phys Oceanogr 45:1339-1355

Bjerknes J (1964) Atlantic air-sea interaction. Advances in Geophysics, vol 10. Academic Press, pp 1-82

Bleck R, Rooth C, Hu D, Smith LT (1992) Salinity-driven theocline transients in a wind- and thermohaline-forced isopycnic coordinate model of the North Atlantic. J Phys Oceanogr 22:1486-1505

Böning CW, Scheinert M, Dengg J, Biastoch A, Funk A (2006) Decadal variability of subpolar gyre transport and its reverberation in the North Atlantic overturning. Geophys Res Lett 33:L21S01

Born A, Mignot J (2012) Dynamics of decadal variability in the Atlantic subpolar gyre: a stochastically forced oscillator. Clim Dyn 39:461-474

Covey C, AchutaRao KM, Cubasch U, Jones P, Lambert SJ, Mann ME, Phillips TJ, Taylor KE (2003) An overview of results from the Coupled Model Intercomparison Project. Glob Planet Change 37:103-133

Curry R, McCartney M, Joyce T (1998) Oceanic transport of subpolar climate signals to mid-depth subtropical waters. Nature 391:575-577

Deque M, Dreveton C, Braun A, Cariolle D (1994) The ARPEGE/IFS atmosphere model: a contribution to the French community climate modelling. Clim Dyn 10:249-266

Divine D, Dick C (2006) Historical variability of sea ice edge position in the Nordic Seas. J Geophys Res 111:C01001

Farneti R, Vallis GK (2013) Meridional energy transport in the coupled atmosphere-ocean system: compensation and partitioning. $\mathrm{J}$ Clim 26:7151-7166

Fauria MM, Grinsted A, Helama S, Moore J, Timonen M, Martma T, Isaksson E, Eronen M (2010) Unprecedented low twentieth century winter sea ice extent in the Western Nordic Seas since A.D. 1200. Clim Dyn 34:781-795

Furevik T, Bentesen M, Drange H, Kindem IKT, Kvamstø NG, Sorteberg A (2003) Description and evaluation of the Bergen climate model: ARPEGE coupled with MICOM. Clim Dyn 21:27-51

Gulev SK, Latif M, Keenlyside N, Park W, Koltermann KP (2013) North Atlantic Ocean control on surface heat flux on mutidecadal timescales. Nature 499:464-468

Held IM (2001) The partitioning of the poleward energy transport between the tropical ocean and atmosphere. J Atmos Sci 58:943-948

Hoskins BJ, Karoly DJ (1981) The steady linear response of a spherical atmosphere to thermal and orographic forcing. J Atmos Sci 38:1179-1196

Jungclaus JH, Koenigk T (2010) Low-frequency variability of the arctic climate: the role of oceanic and atmospheric heat transport variations. Clim Dyn 34:265-279

Kaspi Y, Schneider T (2011) Winter cold eastern continental boundaries induced by warm ocean waters. Nature 471:621-624

Klimenko VV (2008) Reconstruction of climate in the Russian Arctic over the last 600 years based on documentary evidence. Dokl Earth Sci 418:95-98 
Liu Z, Yang H, He C, Zhao Y (2015) A theory for Bjerknes compensation: the role of climate feedback. J Clim 29:191-208. doi:10.1175/JCLI-D-15-0227.1

Miles MW, Divine DV, Furevik T, Jansen E, Moros M, Ogilvie AEJ (2014) A signal of persistent Atlantic multidecadal variability in Arctic sea ice. Geophys Res Lett. doi:10.1002/2013GL058084

Myhre G, Shindell D, Bréon F-M, Collins W, Fuglestvedt J, Huang J, Koch D, Lamarque J-F, Lee D, Mendoza B, Nakajima T, Robock A, Stephens G, Takemura T, Zhang H (2013) Anthropogenic and natural radiative forcing. In: Stocker TF, Qin D, Plattner G-K, Tignor M, Allen SK, Boschung J, Nauels A, Xia Y, Bex V, Midgley PM (eds) Climate change 2013: the physical science basis. Contribution of working group I to the fifth assessment report of the intergovernmental panel on climate change. Cambridge University Press, Cambridge, pp 659-740. doi:10.1017/ CBO9781107415324.018

Oliver K, Heywood K (2003) Heat and freshwater fluxes through the Nordic Seas. J Phys Oceanogr 33:1009-1026

Otterå OH, Bentsen M, Bethke I, Kvamsto NG (2009) Simulated perindustrial climate in Bergen Climate Model (version 2): model description and large-scale circulation features. Geosci Model Dev 2:197-212

Shaffery LC, Sutton RT (2004) The interannual variability of energy transports within and over the Atlantic Ocean in a coupled climate model. J Clim 17:1433-1448

Shaffery LC, Sutton RT (2006) Bjerknes compensation and the decadal variability of energy transports in a coupled climate model. J Clim 19:1167-1181
Smedsrud LH et al (2013) The role of the Barents Sea in the Arctic climate system. Rev Geophys 51:415-449. doi:10.1002/ $\operatorname{rog} .20017$

Svendsen LS, Hetzinger N Keenlyside, Gao Y (2014) Marine-based multiproxy reconstruction of Atlantic multidecadal variability. Geophys Res Lett. doi:10.1002/2013GL059076

Trenberth K, Caron JM (2001) Estimates of meridional atmosphere and ocean heat transports. J Clim 14:3433-3443

Van der Swaluw E, Drijfhout SS, Hazeleger W (2007) Bjerknes compensation at high northern latitudes: the ocean forcing the atmosphere. J Clim 20:6023-6032

Weijers S, Broekman R, Rozema J (2010) Dendrochronology in the High Arctic: July air temperatures reconstructed from annual shoot length growth of the circumarctic dwarf shrub Cassiope tetragona. Quat Sci Rev 29:3831-3842

Yang H, Wang Y, Liu Z (2013) A modelling study of the Bjerknes compensation in the meridional heat transport in a freshening ocean. Tellus A 65:18480

Yang H, Li Q, Wang K, Sun Y, Sun D (2015) Decomposing the meridional heat transport in the climate system. Clim Dyn 44:27512768. doi:10.1007/s00382-014-2380-5

Zeiba A (2010) Effective number of observations and unbiased estimators of variance for autocorrelated data - an overview. Metrol Meas Syst, XVII, pp 3-16 